1 ("MSST")

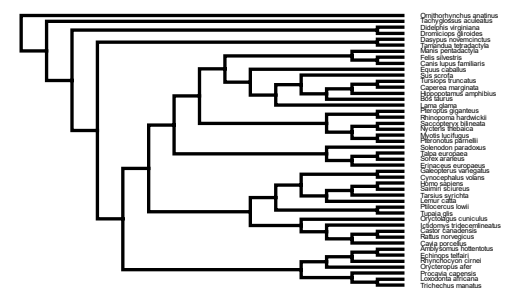

5 ("Carnivora 1")

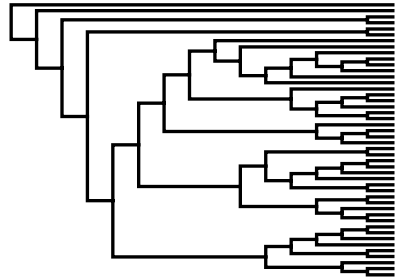

9 ("Cingulata")

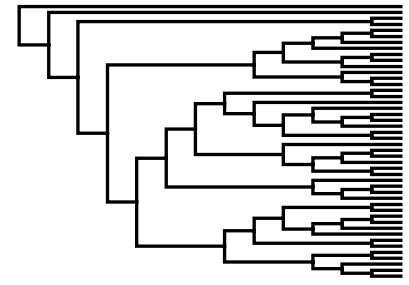

13 ("Hyracoidea")

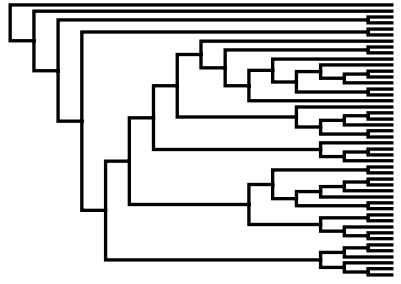

17 ("Perissodactyla")

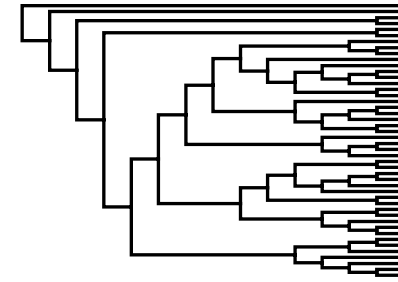

21 ("Proboscidea")

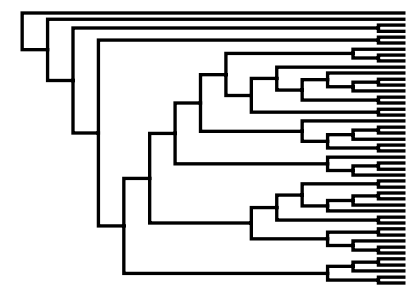

25 ("Sirenia")

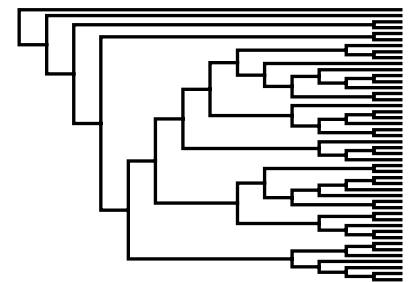

2 ("NoPseudoextinct 1")

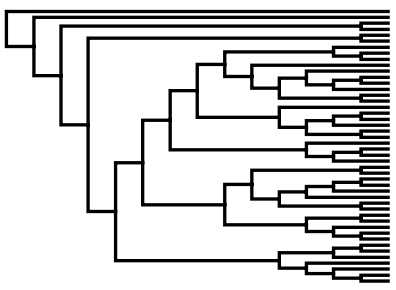

6 ("Carnivora 2")

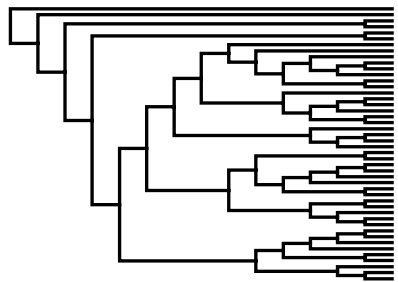

10 ("Dermoptera")

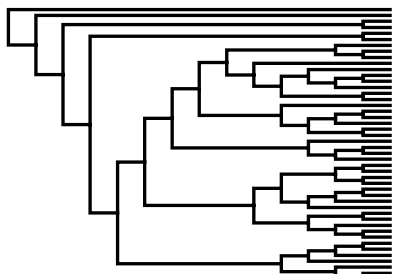

14 ("Lagomorpha")

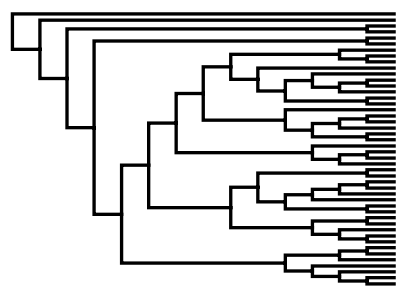

18 ("Pholidota")

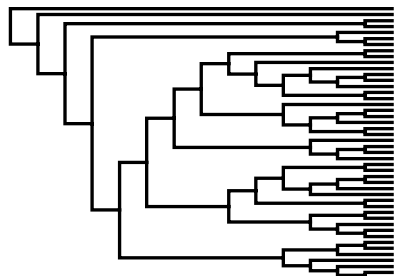

22 ("Rodentia")

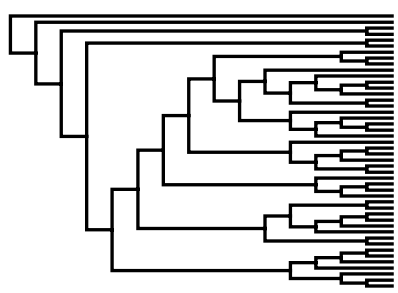

26 ("Tubulidentata 1")

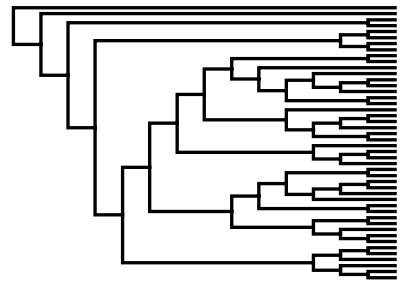

3 ("NoPseudoextinct 2")

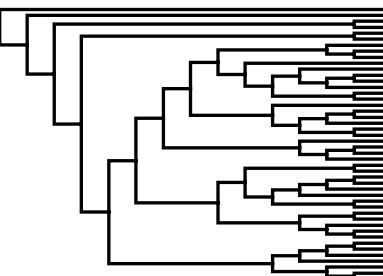

7 ("Cetartiodactyla")

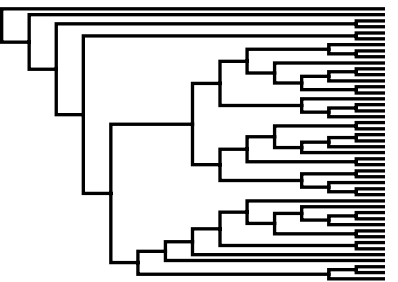

11 ("Eulipotyphla 1")

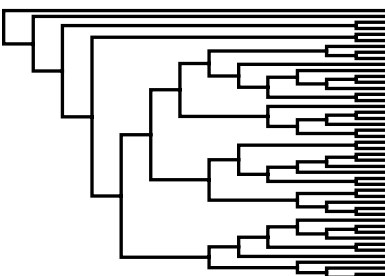

15 ("Macroscelidea 1")

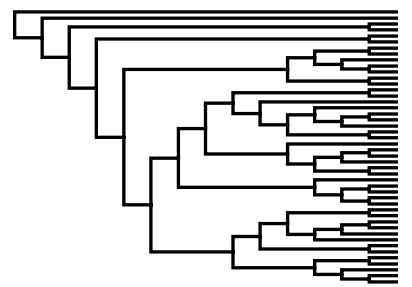

19 ("Pilosa")

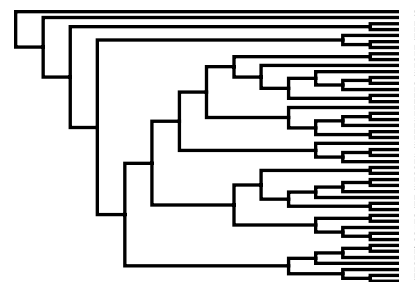

23 ("Scandentia 1")

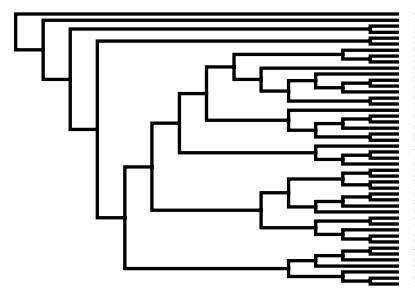

27 ("Tubulidentata 2")

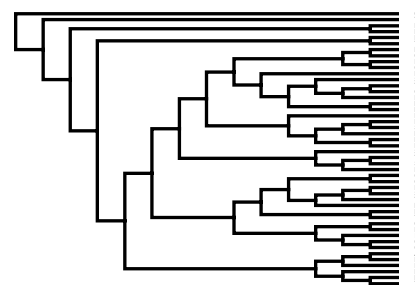

4 ("Afroscoricida")

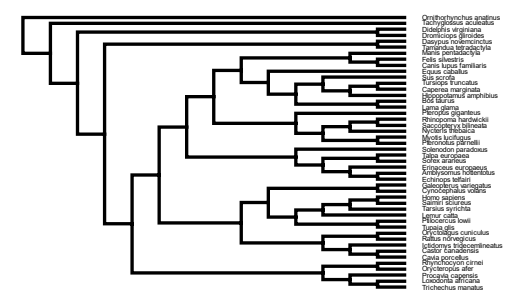

\section{8 ("Chiroptera")}

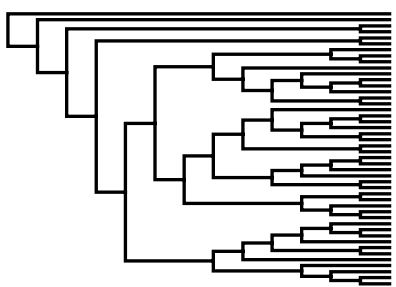

12 ("Eulipotyphla 2")

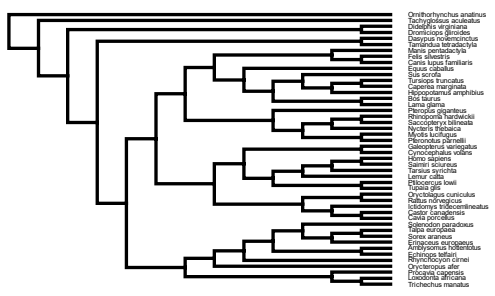

16 ("Macroscelidea 2")

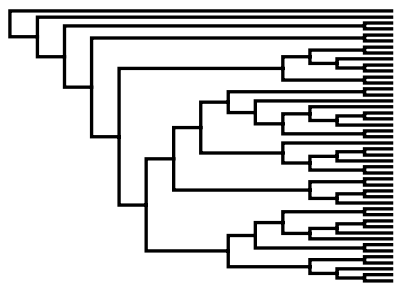

20 ("Primates")

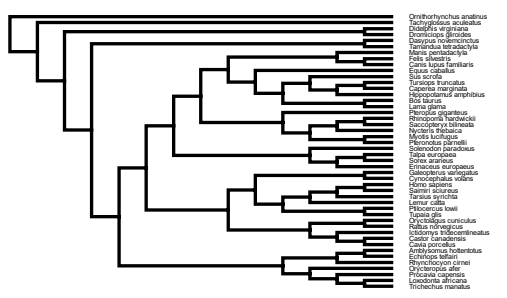

\section{4 ("Scandentia 2")}

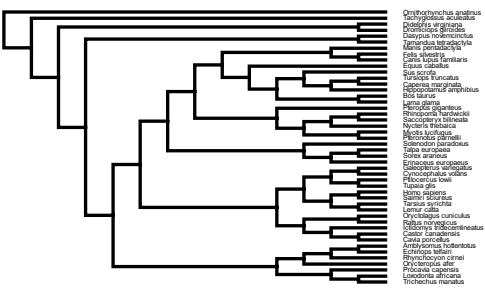

28 ("Tubulidentata 3")

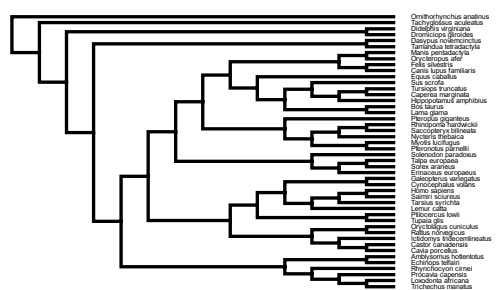

